\title{
Conhecimentos necessários para o ensino de números racionais no Ensino Fundamental
}

\author{
Knowledge required to teach rational numbers in elementary school
}

\author{
Adriana Fátima de Souza Miola \\ Talita Emily de Aguiar Lima
}

Resumo: Este trabalho teve como objetivo investigar os conhecimentos de professores que ensinam Matemática sobre os números racionais. Focamos nesse tipo de números por se tratar de um conteúdo presente nos $5^{\circ}$ e $6^{\circ}$ anos do Ensino Fundamental. Tomamos como base teórica o Conhecimento Matemático para o Ensino (Mathematical Knowledge for Teaching - MKT). Para a produção de dados utilizamos questionários e tivemos como participantes professores de Pedagogia e Matemática. Categorizamos as produções de acordo com o nosso referencial teórico: Conhecimento do Conteúdo e do Currículo (CCK), Conhecimento do Conteúdo e Estudantes (KCS), Conhecimento Horizontal do Conteúdo (HCK), Conhecimento do Conteúdo e Ensino (KCT), Conhecimento Comum do Conteúdo (CCK) e Conhecimento Especializado do Conteúdo (SCK). Concluímos que há lacunas nos conhecimentos matemáticos dos professores participantes. Apontamos, assim, a necessidade de formação continuada que contemple os números racionais.

Palavras-chave: Formação de professores. Conhecimento profissional docente. Números racionais.

\begin{abstract}
This study aimed to investigate the knowledge of teachers who teach mathematics on rational numbers. We focus on this type of numbers because it is the content of the $5^{\text {th }}$ and $6^{\text {th }}$ grades of Elementary School. We take as a theoretical basis the Mathematical Knowledge for Teaching (MKT). For the production of data, we used questionnaires and had as participants teachers of Pedagogy and Mathematics. We categorize the productions according to our theoretical framework: Content and Curriculum Knowledge (CCK), Knowledge of Content and Students (KCS), Horizontal Content Knowledge (HCK), Knowledge of Content and Teaching (KCT), Common Content Knowledge (CCK) e Specialized Content Knowledge (SCK). We conclude that there are gaps in the mathematical knowledge of the participating teachers. Thus, we point out the need for continuous teacher training that includes rational numbers.
\end{abstract}

Adriana Fátima de Souza Miola Doutora em Educação Matemática Professora Programa de Pós-Graduação em Ensino de Ciências e Matemática da Universidade Federal da Grande Dourados (UFGD). Mato Grosso do Sul, Brasil. (iD) orcid.org/0000-0002-4757-2554

$\bowtie$ drica220@yahoo.com.br

Talita Emily de Aguiar Lima Licenciada em Matemática pela da Universidade Federal da Grande Dourados (UFGD). Mato Grosso do Sul, Brasil. iD orcid.org/0000-0002-2965-4564

$\bowtie$ talitaemilly@hotmail.com

Recebido em 30/06/2020 Aceito em 10/08/2020 Publicado em 26/09/2020

Keywords: Teacher training. Professional teaching knowledge. Rational numbers.

\section{Considerações iniciais}

A investigação sobre os conhecimentos docentes tem sido recorrente dentro da área da Educação Matemática. Muitos pesquisadores, como Pimenta (2002), Tardif (2004), Fiorentini e Pereira (1998), Ponte (1992, 1994) e Shulman (1987), mostram preocupação com a necessidade 
do domínio desses saberes e alguns, especificamente, com professores que ensinam Matemática.

Os conhecimentos necessários para o ensino de Matemática envolvem o domínio dos conteúdos abordados na Educação Básica, entre eles os números racionais, principalmente por serem avaliados como um dos que possuem grande distorção ou ausência de conceitos matemáticos materializados nas práticas escolares, e porque os alunos apresentam certo grau de dificuldade para aprendê-los. Algumas pesquisas têm revelado adversidades no ensino e na aprendizagem desse conteúdo, como a de Coelho (2014), que destaca as frações como um dos temas de maior dificuldade para o professor, sendo o assunto escolhido como objeto dos planos de aula nas atividades de formação de professores durante seus estudos.

Batista (2017) também focaliza os números racionais em sua pesquisa e desenvolve, juntamente com professores participantes, atividades envolvendo recursos como software e tangram para $06^{\circ}$ ano do Ensino Fundamental para contribuir na compreensão do conceito de fração. Do mesmo modo, Felix (2010) discutiu, apontou obstáculos, elaborou e produziu exercícios com os números racionais. Com isso, notamos que as dificuldades com o ensino e a aprendizagem dessa temática é recorrente nas pesquisas no campo da Educação Matemática.

Para esclarecer como definimos os números racionais, apresentamos a Figura 1 a seguir.

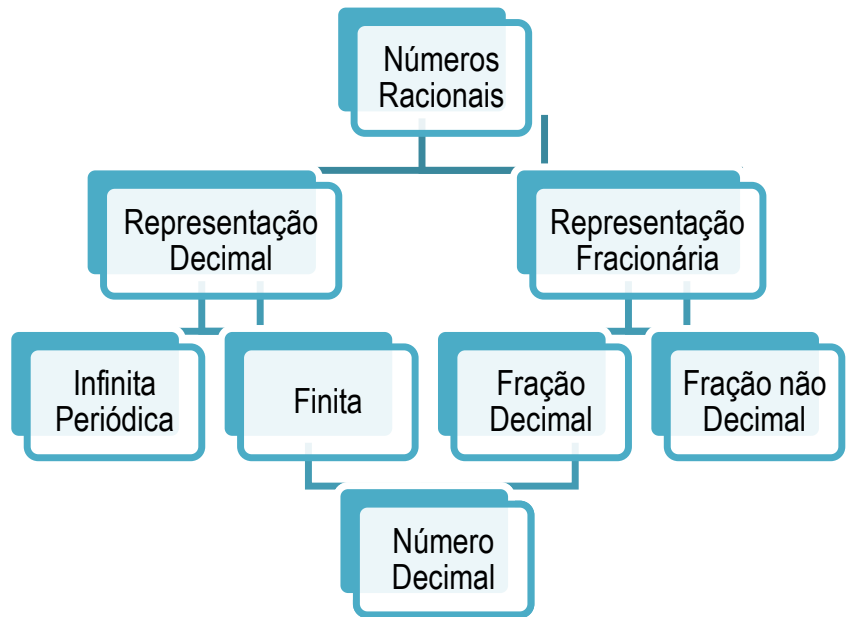

Figura 1: Sistematização dos números racionais (Elaborado pelas Autoras)

A partir dessa estruturação, investigaremos os conhecimentos de professores licenciados em Matemática e Pedagogia, pois o ensino dos números racionais começa nos Anos Iniciais do Ensino Fundamental e é sistematizado nos Anos Finais. Por esse motivo, escolhemos profissionais que atuavam nos $5^{\circ}$ e $6^{\circ}$ anos e, a partir disso, traçamos o seguinte objetivo: investigar os conhecimentos de professores de Matemática sobre os números racionais. Este 
trabalho utilizou a teoria do Conhecimento Matemático para o Ensino (Mathematical Knowledge for Teaching - MKT) desenvolvida por Ball, Thames e Phelps (2008), por tratar do conhecimento específico da Matemática.

Para a compreensão dos leitores, estruturamos este trabalho em quatro seções. A primeira introduz as ideias desenvolvidas para a produção do artigo, incluídos os objetivos, a apresentação e a organização do texto que o compõem; na segunda, apresentamos algumas pesquisas a fim de discutir o que tem sido produzido sobre esse tema, algumas concepções teóricas acerca de saberes e conhecimentos docentes e, na sequência, expomos a nossa opção pelo referencial teórico.

$\mathrm{Na}$ terceira seção revelamos como organizamos os aspectos metodológicos deste trabalho, a abordagem qualitativa, a escolha do questionário como instrumento para produção de dados, os meios utilizados e a seleção dos participantes. Já na quarta, mostramos uma discussão acerca dos dados produzidos pelo questionário e alguns excertos que representam as falas mais recorrentes e que atendem ao nosso objetivo. Ao final, apresentamos os resultados obtidos e deixamos nossas considerações finais a respeito do domínio dos conhecimentos docentes para 0 ensino de Matemática.

\section{Os conhecimentos necessários para o ensino de Matemática}

O conhecimento do professor, tanto de especialistas como de polivalentes, tem sido uma preocupação atual e objeto de estudos e reflexões de vários pesquisadores, tais como Pimenta (2002), Tardif (2002, 2004), Fiorentini e Pereira (1998), Ponte (1992, 1994, 1998) e Shulman (1987), os quais nos auxiliaram na busca por teóricos sobre o tema, pois mostram preocupação com a necessidade do domínio dos saberes para a docência.

Algumas pesquisas também investigaram sobre os conhecimentos docentes. 0 trabalho de Souza (2013), por exemplo, teve como objetivo avaliar quais saberes os profissionais da educação deveriam ter para ensinar e, assim, promover a aprendizagem dos seus alunos. Para isso, utilizou questionários, entrevistas, análise documental e observação da prática docente de professores de Matemática e pedagogos. A autora aponta para lacunas nos conhecimentos necessários para o ensino, justificadas pelas compreensões matemáticas provindas de experiências escolares, formação inicial e continuada desses professores. Ela ressalta que os professores participantes resolvem as situações recorrendo à regra ou ignorando a questão, sem 
dirigir o conhecimento matemático a um caminho que leve ao entendimento do aluno.

Já Silva (2007) analisou os fatores que podem interferir no desenvolvimento profissional de professores dos primeiros anos do Ensino Fundamental, resultando em uma formação continuada que tinha como finalidade discutir a abordagem da representação fracionária de números racionais. A partir de resultados e relatos obtidos no estudo, ficaram nítidas para a autora as dificuldades relativas ao conhecimento matemático na prática dos professores. Assim, Silva (2007) enfatiza a necessidade de se inserir conteúdo específico de Matemática na formação inicial, de maneira que contemple tanto os saberes sobre o tema como os conhecimentos pedagógicos curriculares.

Damico (2007) investigou a formação inicial de professores de Matemática para o ensino dos números racionais no Ensino Fundamental. $O$ autor propôs como produção de dados que os alunos participantes criassem e resolvessem problemas envolvendo frações; posteriormente, avaliou-os; e, em outro momento, entrevistou parte deles juntamente com alguns professores.

O pesquisador enfatiza que os conteúdos da Educação Básica são elementos essenciais do conhecimento profissional do professor de Matemática e, ao longo da pesquisa, verificou que existe uma formação inicial desequilibrada, com enfoque predominante sobre os conteúdos matemáticos e pouca valorização dos componentes didáticos. No que tange aos números racionais, o trabalho destaca que eles não são revisados no curso universitário, nem sob a perspectiva dos aspectos matemáticos nem dos didáticos, tornando parte dos saberes sobre frações apresentados na análise como resquícios de memórias pertencentes à Educação Básica.

Fonseca (2008), por sua vez, toma como foco de sua pesquisa a análise sobre os saberes e não saberes dos professores dos Anos Iniciais do Ensino Fundamental relacionados aos números racionais, investigando como eles foram construídos e orientam a prática docente e quais são as adversidades e as inseguranças sobre o conteúdo. Os resultados apontaram a dificuldade desses profissionais em relação à disciplina, mesmo antes do ensino superior, além de alguns deles, por não terem essa matéria específica no curso de formação inicial, só aprenderem determinados temas após a docência. Dessa forma, a autora alerta para a necessidade da discussão sobre a Matemática Escolar na formação inicial e continuada dos educadores dos Anos Iniciais.

Souza (2013) teve como objetivo investigar quais eram os conhecimentos que os professores deveriam saber para ensinar e, assim, conduzir as aprendizagens dos seus alunos. 
Para a coleta de dados foram utilizados questionários, entrevistas, análise documental e observação da prática docente. A autora conclui que existem lacunas nos conhecimentos necessários para o ensino dos números racionais, justificadas pelas concepções matemáticas provindas de experiências escolares, formação inicial e continuada desses docentes.

A autora ressalta que as dúvidas e as falhas entre os professores se assemelham, sejam eles formados em Matemática ou em Pedagogia, pois observou-se durante a pesquisa que, ao serem questionados pelos alunos que não compreenderam algo, resolvem a situação recorrendo à regra ou ignorando a questão, sem dirigir o conhecimento matemático a um caminho que levasse à compreensão do aluno.

Elias (2017) realizou uma investigação sobre a aproximação entre a Matemática veiculada na Licenciatura em Matemática e a prática docente na Educação Básica. Para o autor, existe um distanciamento entre ambas, tomando como exemplo o ensino dos números racionais, por se tratar de um conceito primordial para o trabalho do professor na escola e que, geralmente, na licenciatura em Matemática, pouco se conecta à prática do educador. Esse trabalho foi dividido em etapas: primeiramente, procurou referenciais que fundamentassem a Matemática na formação de professores. Em seguida, foi realizada uma avaliação em livros didáticos direcionados à Educação Básica e livros do Ensino Superior; foram feitas entrevistas com profissionais dos dois perfis; levantaram-se pesquisas sobre os números racionais tanto na Matemática escolar quanto acadêmica; e procedeu-se à análise de documentos curriculares oficiais que regem ambos. Assim, gerou-se o terceiro momento, as reflexões, que são as interpretações que surgiram dos dados coletados. Por último, tem-se a quarta etapa: na qual foram construídas três tarefas que indicavam as possibilidades para o ensino do corpo dos números racionais na Licenciatura em Matemática. $O$ autor conclui que o ensino desse conteúdo na formação de professores deve ser tomado como foco, e não como um exemplo da estrutura algébrica do corpo.

A partir da apresentação dessas pesquisas, ressaltando que 0 intuito foi compreender 0 que se tem produzido sobre esse tema no meio acadêmico, tenciona-se avançar e contribuir com essa discussão para o campo da Educação Matemática. As investigações supracitadas utilizaram vários teóricos que discutem acerca de conhecimentos e saberes docentes, tais como Tardif (2002), Fiorentini e Pereira (1998), Shulman (1987), Garcia (1998), entre outros. Neste trabalho, optamos por utilizar como embasamento a teoria sobre conhecimento docente de Shulman (1987) e de Ball, Thames e Phelps (2008). 
Shulman (1987) foi um dos pioneiros nessa discussão, pois ele elaborou, em meados da década de 1980, um mapeamento dos programas de pesquisa sobre ensino. Seus trabalhos evidenciaram a preocupação com os conteúdos e com a formação de professores, e de que 0 simples domínio do conhecimento do tema específico não garante, por si só, um ensino eficaz.

No texto de Shulman (1987), identificamos que ele fez uma investigação sobre os conceitos de conhecimentos dos professores em relação aos testes usados nos Estados Unidos durante o século XIX. Ele encontrou alguns exames em arquivos que mostravam como os saberes dos professores eram limitados, observando que por volta de 1875 era exigido do professor um amplo conhecimento específico do conteúdo. Já no século seguinte, as diretrizes deram maior ênfase aos processos pedagógicos realizados pelo educador em sala de aula. Embora essa divisão tenha ocorrido entre os séculos XIX e XX, em textos mais atuais, o pesquisador afirma que essa mudança de foco, de o que ensinar para como ensinar, é um fato recente.

Shulman (1987) critica a dicotomia existente entre o conhecimento do conteúdo específico e o conhecimento pedagógico encontrada em professores nos Estados Unidos, apontando a necessidade de outro eixo: o conhecimento do conteúdo no ensino vinculado aos dois já existentes. Com isso, ele propõe que os educadores precisam ter diferentes tipos de conhecimentos, o que chamou de base de conhecimentos, sendo eles: o conhecimento do conteúdo específico, o conhecimento pedagógico do conteúdo e o conhecimento curricular.

Depois de Shulman (1987) e seus colaboradores, vários pesquisadores desenvolveram e ainda realizam pesquisas sobre o conhecimento profissional dos professores. Alguns deles são: Pimenta (1999), Tardif (2004), Gauthier et al. (1998). Os saberes, na visão desses autores, possuem diversas perspectivas e conceitos. Apresentamos, resumidamente, essas concepções no Quadro 1.

Por meio de tipologias e categorizações diferenciadas dos saberes elencados pelos autores no Quadro 1, identificamos pontos de convergência e reciprocidade. Tardif (2004, p. 36) define os saberes docentes como "um saber plural, formado pelo amálgama, mais ou menos coerente, de saberes oriundos da formação profissional e de saberes disciplinares, curriculares e experienciais". Ou seja, para o autor, a construção dos saberes do professor provém de diversas fontes e se forma a partir da junção delas, não podendo emergir de apenas uma. 
Quadro 1: Saberes docentes

\begin{tabular}{|c|c|c|}
\hline Autores & Tipo de Conhecimento & Classificação \\
\hline Pimenta (1999) & Saberes docentes & $\begin{array}{r}\text { Saberes da experiência, saberes do conhecimento e } \\
\text { saberes pedagógicos. }\end{array}$ \\
\hline $\begin{array}{c}\text { Gauthier } \\
\text { et al. (1998) }\end{array}$ & Saberes docentes & $\begin{array}{r}\text { Saberes curriculares, saberes disciplinares, saberes da } \\
\text { tradição pedagógica, saberes experienciais, saberes } \\
\text { da ação pedagógica, saberes das ciências da } \\
\text { educação. }\end{array}$ \\
\hline $\begin{array}{c}\text { Tardif, Lessard } \\
\text { e Lahaye (1991) }\end{array}$ & Saberes docentes & $\begin{array}{r}\text { Saberes experienciais, saberes disciplinares, saberes } \\
\text { curriculares, saberes da formação profissional (saberes } \\
\text { das ciências da educação, saberes pedagógicos). }\end{array}$ \\
\hline Saviani (1996) & Saberes docentes & $\begin{array}{r}\text { Saber atitudinal, saber crítico-contextual, saber } \\
\text { específico, saber pedagógico e saber didático- } \\
\text { curricular. }\end{array}$ \\
\hline Freire (2009) & Saberes docentes & $\begin{array}{r}\text { Não há docência sem discência, ensinar não é transferir } \\
\text { conhecimento e ensinar é uma especificidade humana. }\end{array}$ \\
\hline
\end{tabular}

Fonte: Elaborado pelas Autoras

Gauthier et al. (1998) acreditam ser necessário existir um saber teórico sobre o ensino, e que parte dele precisa se iniciar na atividade da sala de aula, dando, assim, importância ao conhecimento decorrente das práticas pedagógicas.

Para Pimenta (1999), o saber da experiência seria aquele aprendido pelo professor desde aluno, em um processo de reflexão e troca com os colegas. $O$ saber do conhecimento abrange a revisão da função da escola na transmissão dos conhecimentos e as suas especialidades em um contexto contemporâneo. Já o saber pedagógico abarca o conhecimento juntamente com o saber da experiência e dos conteúdos específicos, construído a partir das necessidades pedagógicas em contextos reais.

Nesse sentido, Saviani (1996) compreende que os homens "não nascem sabendo sentir, pensar, avaliar, agir. Para saber pensar e sentir, para saber querer, agir ou avaliar, é preciso aprender, o que implica o trabalho educativo" (p. 147). 0 autor acrescenta que o saber a que se refere emerge como resultado do processo de aprendizagem, denominado de fenômeno educativo. Este se configura exigindo que o professor domine alguns saberes - atitudinal, críticocontextual, específico, pedagógico e didático-curricular - para o exercício da docência.

A categorização de Freire (2009) não apresenta conceitos fechados; ele propõe uma 
reflexão crítica para reestruturação e formação de novas concepções. Nas palavras de Tardif (2004),

\begin{abstract}
não provêm das instituições de formação nem dos currículos. Estes saberes não se encontram sistematizados em doutrinas ou teorias. São saberes práticos (e não da prática: eles não se superpõem à prática para melhor conhecê-la, mas se integram a ela e dela são partes constituintes enquanto prática docente) e formam um conjunto de representações a partir das quais os professores interpretam, compreendem e orientam sua profissão e sua prática cotidiana em todas as suas dimensões. Eles constituem, por assim dizer, a cultura docente em ação (p. 48-49).
\end{abstract}

A partir das categorias apresentadas, inferimos, de acordo com os autores, que a formação do professor é cercada de saberes, de diversos contextos e de singularidades, pertencentes tanto ao âmbito acadêmico quanto ao das experiências provindas do exercício de sua profissão, contribuindo para seu desenvolvimento e desempenho.

Nas afirmações dos autores citados, identificamos também que se referem ao professor como alguém que não só apreende saberes, mas também os produz e reproduz por meio de suas práticas. Notamos, ainda, uma aproximação na compreensão de que a formação para a docência procura um olhar para o educador enquanto indivíduo, constituído particular e coletivamente.

A busca por autores que fomentassem essas discussões sobre conhecimentos e saberes relacionados à docência nos levou a identificar alguns estudiosos que tratam especificamente do conhecimento para docência na Educação Matemática, dentre eles destacamos Deborah Ball, a qual, juntamente com seus colaboradores, desenvolveu uma teoria de base prática sobre 0 conhecimento matemático para a docência.

Partindo da pesquisa realizada por Shulman (1987), Ball, Thames e Phelps (2008) propõem o Conhecimento Matemático para o Ensino (Mathematical Knowledge for Teaching MKT), pois compreendem que o termo conhecimento pedagógico do conteúdo sugere a necessidade de um "conhecimento do conteúdo que é exclusivo para o ensino" (p. 389). Entretanto, discordam, principalmente, da generalidade que foi dada, naquela época, ao termo cunhado por Shulman (1987).

Com isso, Ball, Thames e Phelps (2008) apresentam uma ampliação em nível de detalhamento das categorias de conhecimento específico do conteúdo e conhecimento pedagógico do conteúdo definidas por Shulman (1987), conforme mostra a Figura 2. 


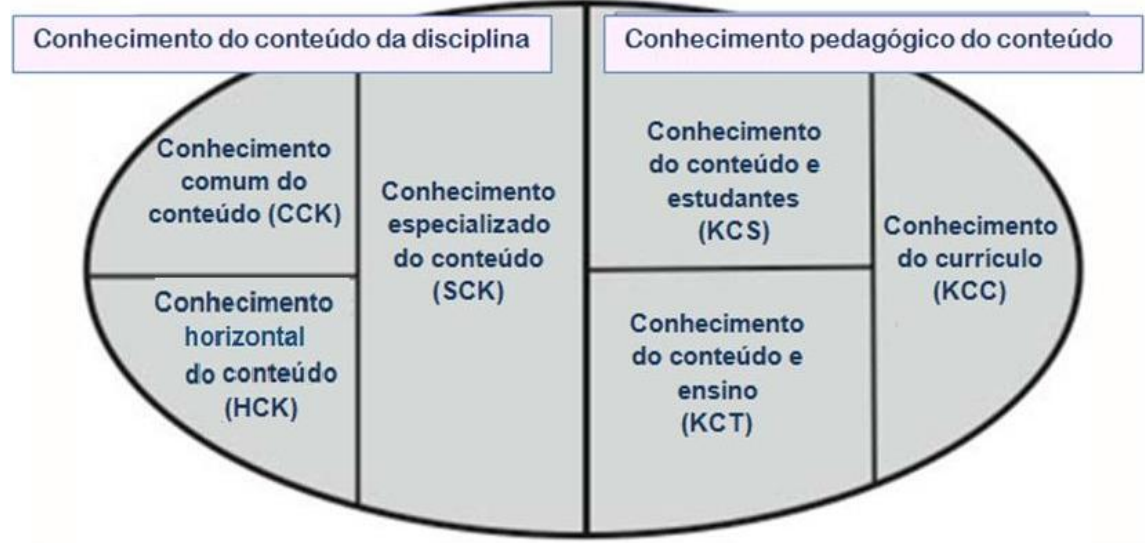

Figura 2: Conhecimento Matemático para o Ensino (BALL, THAMES e PHELPS, 2008, p. 403)

Para esses autores, o modelo sobre o Conhecimento Matemático para o Ensino (MKT) é sobre o conhecimento matemático necessário para se ensinar Matemática. 0 conhecimento do conteúdo da disciplina envolve o Conhecimento Comum do Conteúdo (CCK), que é o de quem sabe e utiliza a Matemática; o Conhecimento Horizontal do Conteúdo (HCK) é um conjunto mais amplo de ideias ao qual uma ideia se conecta; e o Conhecimento Especializado do Conteúdo (SCK) é aquele necessário só para quem ensina.

Já dentro do conhecimento pedagógico do conteúdo, eles destacam o Conhecimento do Conteúdo e Estudantes (KCS), que se refere à tomada de decisões sobre o que fazer quanto às dificuldades dos alunos; o Conhecimento do Currículo (KCC), que tem por finalidade a estruturação curricular; e o Conhecimento do Conteúdo e Ensino (KCT), o qual diz respeito à possibilidade de tornar-se um tópico difícil/fácil para os alunos, ou às maneiras pelas tendem a desenvolver uma compreensão de uma determinada ideia.

Neste trabalho, ao investigar os conhecimentos dos professores que ensinam Matemática sobre os números racionais, utilizaremos na análise dos dados o trabalho de Ball, Thames e Phelps (2008) no que tange ao conhecimento para o ensino de Matemática.

\section{Aspectos metodológicos}

Este trabalho foi de cunho qualitativo, uma vez que seu objetivo não se detém aos aspectos quantitativos, nesse caso, os conhecimentos para o ensino de Matemática. Como explica Moreira (2002), a pesquisa qualitativa possui como foco a interpretação, tem como ênfase a subjetividade, concentrando-se na perspectiva dos participantes, possui flexibilidade na condução do estudo, o interesse da pesquisa está na construção do seu processo, não em seu resultado, 
entre outras características. A esse respeito, Richardson (1999, p. 79) pondera que "a abordagem qualitativa de um problema, além de ser uma opção do investigador, justifica-se, sobretudo, por ser uma forma adequada para entender a natureza de um fenômeno social".

Assim, determinada que a abordagem seria qualitativa, escolhemos como instrumento de produção de dados o questionário, elaborado com sete questões que versavam sobre a maneira como os professores de Matemática e pedagogos criavam e desenvolviam o ensino de números racionais nos $5^{\circ}$ e $6^{\circ}$ anos do Ensino Fundamental. Coletamos as respostas de 11 professores, sendo seis de Matemática e cinco pedagogos, todos atuantes em escolas da rede pública de Dourados (MS), no primeiro semestre de 2019. A partir das respostas obtidas, categorizamo-las por meio dos conhecimentos apontados por Ball, Thames e Phelps (2008), identificando os participantes como Professores de Matemática (PM) e Professores Pedagogos (PP).

\section{Discussão dos resultados}

Organizamos os dados produzidos e a análise foi construída pelas respostas textualizadas provenientes dos questionários desenvolvidos. As sete questões sobre o ensino de números racionais possibilitaram que os professores explicitassem seus conhecimentos sobre esse conteúdo, os quais são apresentados nas subseções a seguir. Destacamos os excertos que representavam as afirmações mais recorrentes e que atingiam o nosso objetivo.

\subsection{Conhecimento do conteúdo da disciplina}

No que concerne aos conhecimentos específicos do conteúdo, sendo eles os Conhecimentos Especializado (SCK), Comum (CCK) e Horizontal (HCK), foi possível inferir por meio das respostas obtidas que os professores possuem lacunas referentes a esses saberes. Ao serem questionados sobre como compreendem os números racionais, responderam:

A meu ver, a fração é usada para indicar uma parte de um inteiro, por exemplo eu tenho uma pizza de 8 pedaços e eu comi 2 pedaços dela. Como eu colocaria isso em fração? Dois oitavos. Então, ela indica a parte de um inteiro. Os decimais são indicados pela vírgula, e ele indica décimos e não um número inteiro (PP 1, 2019).

Racionais são números que podem ser escritos na forma de fração. Números racionais são números racionais, não inteiros expressos por vírgulas e que possuem casas decimais (PP 4, 2019).

É uma divisão (PP 5, 2019). 
Defino número racional como qualquer número que se possa escrever em forma de fração, a fração como a divisão de dois números inteiros e o número decimal como uma outra maneira de se escrever uma fração (PM 2, 2019).

É uma divisão entre dois números inteiros, isso é um número racional. Uma fração é a forma como apresento um número racional e o número decimal é outra maneira de escrever uma fração, isso dentro dos racionais e é claro que existem alguns números decimais que não pode ser escrito como uma fração, posso dar alguns exemplos como pi (PM 4, 2019).

Fração é a parte de algo, quantas partes você utiliza de um todo. Número decimal é todo número que vem depois da vírgula, que pertence a ordem decimal e pode ser escrito como fração (PM 5, 2019).

Nessas declarações identificamos a falta de domínio referente ao conhecimento específico, principalmente no tocante à definição de números decimais, pois, como vimos na Figura 1, os decimais possuem suas representações, a decimal e a fracionária, e, por definição, um número decimal é uma representação (decimal) de números racionais, contrariando as definições dos excertos acima.

Embora os pedagogos tenham criticado a formação matemática que receberam na formação inicial e, por consequência, encontram dificuldades no ensino de vários conteúdos matemáticos, notamos que os professores de Matemática, que tiveram uma formação mais específica nos conceitos matemáticos, também mostraram falta de conhecimento no que se refere aos números racionais.

Na fala do PM 4, ao dar o exemplo do número pi como um número decimal que não pode ser escrito na forma de fração, ele comete dois equívocos: um deles é considerar o pi pertencente aos números racionais, e outro é confundir um número com sua representação, pois há número decimal que pode ser representado por uma fração decimal ou por sua representação decimal finita; o número pi possui uma representação decimal infinita e não periódica.

Desse modo, é fundamental o domínio da disciplina, posto que envolve o Conhecimento Comum do Conteúdo (CCK), que permite o reconhecimento de uma resposta errada dos alunos; dimensionar rapidamente a natureza de um erro, principalmente aqueles que não são familiares, sendo esse o Conhecimento Especializado do Conteúdo (SCK); possibilitar ao professor saber como os conteúdos matemáticos são construídos conceitualmente ao longo do currículo - $\underline{0}$ Conhecimento Horizontal do Conteúdo (HCK). De acordo com Ball, Thames e Phelps (2008), a ausência de algum desses conhecimentos pode prejudicar o trabalho desse profissional e atrapalhar seu desempenho em sala de aula.

Outro conhecimento necessário para o ensino de Matemática é o pedagógico do 
conteúdo, o qual está relacionado à capacidade do professor de transformar o seu conhecimento do conteúdo em formas pedagógicas e eficazes, fazendo adaptações de várias situações em função das necessidades de aprendizagem de seus alunos.

\subsection{Conhecimento pedagógico do conteúdo}

O conhecimento pedagógico do conteúdo foi subdividido em outros três por Ball, Thames e Phelps (2008), sendo eles: Conhecimentos do Currículo (KCC); do Conteúdo e Estudantes (KCS); e do Conteúdo e Ensino (KCT). Nas respostas obtidas sobre as dificuldades que os alunos apresentam na aprendizagem desses conceitos, e como os professores ensinam os números racionais, tivemos as seguintes declarações:

Meus alunos tiveram dificuldade e optei por aula prática, usando pizza e outras formas (PP 4, 2019).

Eu percebi que os alunos têm muita dificuldade na divisão e nas frações, desde 0 terceiro ano e vem carregando isso porque até os professores não aprenderam os conteúdos direito no curso (PP 5, 2019).

Os alunos sentem muita dificuldade porque eles não aprenderam o conceito, por isso eu sempre optei por trabalhar o lúdico, com elementos palpáveis e de uma forma que tornasse comum ao aluno (PM 1, 2019).

Quando trabalhei com $06^{\circ}$ ano não usei, porém, tento adaptar, nas minhas turmas algumas das situações com exemplos práticos ou alguma atividade que relacione 0 conteúdo e algo diferenciado, como paródias e mapas conceituais, por exemplo (PM 3, 2019).

Esse conteúdo, geralmente, eu trabalho com, ou desenho de disco e barras, ou situações-problema envolvendo frações e números decimais (PM 4, 2019).

Os professores pedagogos, de modo geral, responderam que os alunos apresentam muita dificuldade, e que eles recorrem sempre a recursos didáticos que conheceram durante a formação inicial. Entretanto, ressaltam a fragilidade na formação específica que repercute na aprendizagem dos alunos, como aparece na fala de PP 5.

Já os professores de Matemática mostraram bastante familiaridade com materiais pedagógicos e outros métodos de ensino. Além disso, ter experiência com os erros comuns e saber por que diversos alunos os cometem é um Conhecimento de Conteúdo e Estudantes (KCS); e selecionar uma abordagem de ensino que seja eficiente para superar certas dificuldades e/ou explorar determinados aspectos de um conteúdo é um Conhecimento do Conteúdo e Ensino $(\mathrm{KCT})$. 
O Conhecimento do Conteúdo e Estudantes (KCS) engloba o conhecimento sobre os alunos e sobre o fato de saber Matemática. Os professores devem, por exemplo, ser capazes de antecipar o que os alunos estão propensos a pensar e o que e quando eles encontrarão dificuldades acerca de um determinado conteúdo; Conhecimento do Conteúdo e Ensino (KCT) combina o saber sobre o ensino e sobre matemática. Muitas das tarefas matemáticas de ensino exigem um conhecimento matemático da organização dos conteúdos específicos para o ensino; Conhecimento do Currículo (KCC) é um subdomínio do conhecimento pedagógico do conteúdo.

Ball, Thames e Phelps (2008) apontam ser necessário que o professor tenha uma visão completa da diversidade de programas concebidos para o ensino de temas e os conteúdos em determinado nível/ano de escolaridade, como também da variedade de materiais didáticos disponíveis, corroborando integralmente o que é apontado por Shulman (1987). Nesse sentido, alertam que os professores devem ser capacitados para antecipar possíveis dificuldades de assimilação que os alunos possam apresentar ao tratar de certos temas.

Para isso, é necessário que o professor procure formas de melhorar o seu ensino, pesquisando outras maneiras, além da tradicional, de ensinar e abordar os conteúdos matemáticos, construindo com o aluno o raciocínio matemático por meio de recursos didáticos variados, mostrando a utilidade e a importância da matemática, tornando a aprendizagem possível, acessível e interessante.

\section{Algumas considerações}

Nesta pesquisa nos propusemos a investigar os conhecimentos de professores de Matemática sobre os números racionais, utilizando os conhecimentos advindos da teoria de MKT de Ball, Thames e Phelps (2008). Empregamos seus domínios: Conhecimento do Currículo (KCC), Conhecimento do Conteúdo e Estudantes (KCS), Conhecimento Horizontal do Conteúdo (HCK), Conhecimento do Conteúdo e Ensino (KCT), Conhecimento Comum do Conteúdo (CCK) e Conhecimento Especializado do Conteúdo (SCK). Estes são interpretados e constituem os conhecimentos propostos por Shulman (1987): o conhecimento pedagógico do conteúdo e 0 conhecimento específico do conteúdo.

Após a análise dos resultados, concluímos ser preciso voltar nosso olhar para a formação inicial nos cursos de Pedagogia e Licenciatura em Matemática, pois existem problemas em relação à construção desses conhecimentos, posto que muitos professores contornaram a situação por 
conta própria e por meio da prática em sala de aula. Além disso, é necessário, também, darmos atenção à formação pois, como vimos, os professores participantes não tiveram o conteúdo dos números racionais ofertado em suas formações, mesmo sendo um tema de difícil compreensão para os alunos, conforme relataram.

Assim, para que em um ensino ocorra aprendizagem, é desejável que os professores que ensinam Matemática e atuam no $5^{\circ}$ e $6^{\circ}$ anos do Ensino Fundamental tenham, de acordo com Ball, Thames e Phelps (2008), mais do que o Conhecimento Comum do Conteúdo (CCK), o Conhecimento Especializado do Conteúdo (SCK), o Conhecimento Horizontal do Conteúdo (HCK), o Conhecimento do Conteúdo e Estudantes (KCS), o Conhecimento do Conteúdo e Ensino (KCT) e o Conhecimento do Currículo (KCC). Em outras palavras, um bom ensino de Matemática deverá resultar em uma compreensão significativa de conceitos e procedimentos, bem como compreensões a respeito da disciplina e sobre o que significa fazer Matemática.

Apontamos, assim, a necessidade de investigações contínuas nas formações inicial e continuada de professores da Educação Básica para a docência, de formação matemática e pedagógica, como também de formações que propiciem aos professores oportunidades de refletir sobre as suas práticas cotidianas e examinar outras, para aprender mais sobre os seus alunos.

\section{Referências}

BALL, Deborah. L.; THAMES, Mark Hoover; PHELPS, Geoffrey. Content knowledge for teaching: what makes it special? Journal of Teacher Education, v. 59, n. 5, p. 389-407, nov. 2008.

BATISTA, Carolina Cordeiro. O estudo de aula na formação de professores de Matemática para ensinar com tecnologia: a percepção dos professores sobre a produção de conhecimento dos alunos. 2017. 109f. Dissertação (Mestrado em Educação Matemática) — Instituto de Geociências e Ciências Exatas. Universidade Estadual Paulista. Rio Claro.

COELHO, Felipe Gomes. A metodologia da lesson study na formação de professores: uma experiência com licenciandos de Matemática. 2014. 321f. Dissertação (Mestrado em Ensino de Matemática) - Instituto de Matemática. Universidade Federal do Rio de Janeiro. Rio de Janeiro.

DAMICO, Alecio. Uma investigação sobre a formação inicial de professores de matemática para o ensino de números racionais no Ensino Fundamental. 2007. 313f. Doutorado (Educação Matemática) - Faculdade de Ciências Exatas e Tecnologias. Pontifícia Universidade Católica de São Paulo. São Paulo.

ELIAS, Henrique Rizek. Fundamentos teórico-metodológicos para o ensino do corpo dos números racionais na formação de professores de Matemática. 2017. 327f. Tese (Doutorado em Ensino de 
Ciências e Educação Matemática) - Centro de Ciências Exatas. Universidade Estadual de Londrina. Londrina.

FELIX, Thiago Francisco. Pesquisando a melhoria de aulas de Matemática segundo a Proposta Curricular do Estado de São Paulo, com a metodologia da Pesquisa de Aulas (Lesson Study). 2010. 153f. Dissertação (Mestrado em Ciências Exatas) - Centro de Ciências Exatas e de Tecnologia. Universidade de São Carlos. São Carlos.

FIORENTINI, Dario; PEREIRA, Elisabete Monteiro de Aguiar. (Org.). Cartografias do trabalho docente: professor(a)-pesquisador(a). Campinas: Mercado das Letras, 1998.

FONSECA, Herika Nunes Torres. Os números racionais nos Anos Iniciais do Ensino Fundamental: investigando saberes docentes. 2008. 133f. Dissertação (Mestrado em Educação) — Faculdade de Educação. Universidade Federal de Minas Gerais. Belo Horizonte.

FREIRE, Paulo. Pedagogia da autonomia: saberes necessários à prática educativa. 42. ed. São Paulo: Paz e Terra, 2009.

GARCIA, Carlos Marcelo. Pesquisa sobre formação de professores: o conhecimento sobre aprender a ensinar. Tradução de Lólio Lourenço de Oliveira. Revista Brasileira de Educação, Rio de Janeiro, n. 9, p. 51-75, set./dez. 1998.

GAUTHIER, Clermont; MARTINEAU, Stéphane; DESBIENS, Jean-François; MALO, Annie; SIMARD, Denis. Por uma teoria da Pedagogia. ljuí: Editora Unijuí, 1998.

MOREIRA, Daniel Augusto. O método fenomenológico na pesquisa. São Paulo: Pioneira Thomson, 2002.

PIMENTA, Selma Garrido. Formação de professores: identidade e saberes da docência. In: PIMENTA, Selma Garrido (Org.). Saberes pedagógicos e atividade e docente. São Paulo: Cortez, 1999.

PIMENTA, Selma Garrido. Professor reflexivo: construindo uma crítica. In PIMENTA. Selma Garrido, GHEDIN, Evandro. (Org.). Professor reflexivo no Brasil: gênese e crítica de um conceito. 2. ed. São Paulo: Cortez, 2002, p. 12-52.

PONTE, João Pedro da. Concepções dos professores de Matemática e processos de formação. In: PONTE, João Pedro da. Educação Matemática: temas de investigação. Lisboa: Instituto de Inovação Educacional, 1992, p. 185-239.

PONTE, João Pedro da. Da formação do desenvolvimento profissional. In: ENCONTRO NACIONAL DE PROFESSORES DE MATEMÁTICA, 1998, Guimarães. Actas do ProfMat1998. Lisboa: APM, 1998, p. 27-44.

PONTE, João Pedro da. O desenvolvimento profissional do professor de Matemática. Educação e Matemática, Lisboa, n. 31, p. 9-12, abr./jun. 1994.

RICHARDSON, Roberto Jarry. Pesquisa Social: métodos e técnicas. São Paulo: Atlas. 1999. 
SAVIANI, Demerval. Educação: do senso comum à consciência filosófica. 12. ed. Campinas: Autores Associados, 1996.

SHULMAN, Lee S. Knowledge and teaching: foundations of the new reform. Harvard Education Review, v. 57, n. 1, p. 1-22, apr. 1987.

SILVA, Angélica da Fontoura Garcia. O desafio do desenvolvimento profissional docente: análise da formação continuada de um grupo de professores das séries iniciais do Ensino Fundamental, tendo como objeto de discussão o processo de ensino e aprendizagem das frações. 2007. $308 f$. Doutorado (Educação Matemática) - Faculdade de Ciências Exatas e Tecnologias. Pontifícia Universidade Católica de São Paulo. São Paulo.

SOUZA, Gresiela Ramos de Carvalho. Números Racionais: concepções e conhecimento profissional de professores e as relações com o livro didático e a prática docente. 2013. 230f. Dissertação (Mestrado em Educação) - Instituto de Educação. Universidade Federal de Mato Grosso. Cuiabá.

TARDIF, Maurice. Saberes docentes e formação profissional. Tradução de Tradução de Francisco Pereira de Lima. 4. ed. Petrópolis: Vozes, 2004.

TARDIF, Maurice; LESSARD, Claude; LAHAYE, Louise. Os professores face ao saber: esboço de uma problemática do saber docente. Tradução de Léa Pinheiro Paixão. Teoria \& Educação, Porto Alegre, n. 4, p. 215-233, 1991. 